\title{
O CONCEITO DE PROFESSOR REFLEXIVO: UMA ANÁLISE SOBRE AS CONCEPÇÕES DE PROFESSORES DE CIÊNCIAS
}

\author{
Glaucia Britto Barreiros ${ }^{1}$, Juliane Maria Bergamin Bocardi ${ }^{2}$, Dulcinéia Ester Pagani Gianotto ${ }^{3}$ \\ ${ }^{1}$ Universidade Estadual de Maringá-UEM, Pós-graduando no curso de Doutorado em Educação para Ciências e a \\ Matemática-PCM, Departamento de Ciências Exatas-DCE, Maringá, PR. E-mail: glaucia_bb@hotmail.com \\ ${ }^{2}$ Universidade Tecnológica Federal do Paraná, Docente do Departamento de Ensino de Química, Medianeira, PR. \\ ${ }^{3}$ Universidade Estadual de Maringá-UEM, Docente do Departamento de Ciências Biológicas-DBI, Maringá, PR.
}

\section{RESUMO}

O conceito de reflexão da prática introduzido na década de 80 , é atualmente fruto de inúmeras pesquisas na formação de professores. Nesse sentido, o objetivo do artigo foi de investigar as concepções de professores atuantes acerca do conceito "professor reflexivo". A pesquisa é de caráter qualitativo, e os atores da pesquisa, foram professores de Ciências e Biologia da cidade de Maringá. Os dados foram constituídos por meio de questionário semiestruturado. Os resultados foram as análises dos trechos das falas dos professores. Destacou-se nas falas que os professores têm a pretensão de aprimorar-se enquanto profissional e a buscam melhorias em suas atuações práticas. A investigação proporcionou um momento de reflexão para estes professores, incentivando não só, as reflexões e ações individuais, mas tecendo um diagnóstico do termo "professor reflexivo", em voga na Educação, investigações dessa natureza fazem-se necessárias, pois direcionam futuras ações na formação de professores (inicial e continuada).

Palavras-chave: Prática reflexiva, Professores atuantes, Ensino reflexivo, Ensino de Ciências e Biologia.

\section{THE REFLECTIVE TEACHER CONCEPT: AN ANALYSIS OF THE VIEWS THE CIENCE TEACHERS}

\begin{abstract}
The concept of practical reflection introduced in the $80 \mathrm{~s}$, is currently the result of extensive research in teacher education. In this sense, the purpose of the article was to investigate the conceptions of teachers working on the concept " reflective teacher ". The research is qualitative, and the actors of the research, were professors of science and biology of the city of Maringá-PR. The data were recorded using a semi-structured questionnaire. The results were the analysis of excerpts from the speeches of teachers. It was emphasized in the speeches that teachers have the intention to improve yourself as a professional and to seek improvements in their practice performances. The research provided a moment of reflection for these teachers, encouraging not only the reflections and individual stocks, but weaving a diagnosis of the term " reflective teacher ", in vogue in education, such investigations are necessary because direct future actions in teacher training ( initial and continuing ) and to seek improvements in their practice performances.

Keywords: Reflective practice, active teachers, reflective Education, Science and Biology Education.
\end{abstract}


INTRODUÇÃO

Nas novas tendências investigativas acerca da formação de professores, encontram-se ideias de autores como Nóvoa (1992), Freire (1996) e Pimenta; Ghedin (2002), que introduzem a concepção do professor como profissional e Schön (1992), que considera o processo de conhecimento profissional centrado na ação, ressaltando o papel da reflexão na ação docente e concebendo o professor reflexivo, definindo um novo perfil do professor. Além de reflexivo, o professor se desenvolveria como um profissional autônomo, investigador e com competências específicas e especializadas que repousam sobre uma base de conhecimentos racionais, reconhecidos e legitimados pela universidade (conhecimentos científicos), ou de conhecimentos advindos da práxis social (ZEICHNER, 2008, PIMENTA; GHEDIN 2002). Nesse sentido, o objetivo deste estudo foi investigar as concepções de professores atuantes acerca do conceito "professor reflexivo".

\section{METODOLOGIA}

No sentido de avançar e contribuir para os estudos sobre a reflexão na formação de professores foi realizada uma pesquisa de cunho qualitativo, como foco o processo da pesquisa, pois se apresenta de maneira subjetiva, onde as variáveis não podem ser controladas (LUDKE \& ANDRÉ, 1986). Os atores da pesquisa se caracterizam como professores de Ciências e Biologia, selecionados aleatoriamente dentro dos colégios da rede pública e privada da cidade de Maringá - Paraná. A princípio foram elencados 25 professores, porém destes apenas 7 realmente se propuseram a participar e responderam as questões, identificados pela sigla P1 (Professor 1) à P7 (Professor 7). 0 questionário semiestruturado foi composto por questões discursivas sobre a perspectiva reflexiva na prática docente, sendo a primeira um "memorial reflexivo", adaptado de Gonzaga (2013), a fim de que os atores elencassem e refletissem acerca dos aspectos da formação; possíveis dificuldades e reflexões da trajetória na profissão. Este artigo é parte da análise de dados da dissertação de mestrado $(C E P)^{1}$. Os dados constituídos foram submetidos a análise de conteúdo utilizando-se do cruzamento dos dados, por meio da categorização proposta por Bardin (1977, p. 117), que é "uma operação de classificação de elementos constitutivos de um conjunto, por diferenciação e, seguidamente, por reagrupamento segundo gênero (analogia), com os critérios previamente definidos". Resultando em três categorias de análise: 1) Histórico de formação dos professores e o reflexo na atuação; 2) Autoavaliação dos professores e 3) Aspectos que dificultam a reflexão dos professores.

\footnotetext{
${ }^{1}$ Número do CAAE - 25702814.9.0000.0104. 
RESULTADOS

Cada professor elaborou seu memorial reflexivo (MR), descrevendo onde, quando e como era sua formação inicial,relacionando estes fatos, com sua formação. Inicialmente foi organizado o perfil destes professores, sintetizando no quadro I uma panorama do MR :

Quadro I. Perfil dos professores participantes e síntese do conteúdo dos Memoriais reflexivos.

\begin{tabular}{|c|c|c|c|}
\hline Sigla & $\begin{array}{l}\text { Ano de } \\
\text { formação/ } \\
\text { Atua em } \\
\text { escola }\end{array}$ & $\begin{array}{l}\text { Sexo/ } \\
\text { Idade }\end{array}$ & Sintese do conteúdo do Memorial Reflexivo \\
\hline P1 & $\begin{array}{c}\text { 2010/ } \\
\text { particular }\end{array}$ & $M / 24$ & $\begin{array}{c}\text { Durante a formação apresenta um crescimento, uma maior criticidade ao realizar } \\
\text { questionamentos, aprendeu a ouvir os alunos e sempre repensar o ensino. }\end{array}$ \\
\hline P2 & $\begin{array}{l}\text { 1994/ } \\
\text { público }\end{array}$ & $\mathrm{F} / 43$ & $\begin{array}{l}\text { Entende que é muito importante todos se reciclarem e buscar melhorar. Apresenta } \\
\text { algumas aspectos como a estrutura da escola, participação mais efetiva da família, } \\
\text { um efetivo plano de educação que não sofresse interferência política e melhoria } \\
\text { salarial. }\end{array}$ \\
\hline P3 & $\begin{array}{c}\text { 2007/ } \\
\text { público }\end{array}$ & $\mathrm{F} / 42$ & Descobriu depois que começou a atuar que ainda tinha muito a aprender. \\
\hline P4 & $\begin{array}{c}\text { 2010/ } \\
\text { público }\end{array}$ & $\mathrm{F} / 27$ & $\begin{array}{l}\text { Acredita que a formação foi boa e que seu desempenho é satisfatório“porém o } \\
\text { professor é um profissional em constante formação que ela sempre busca. }\end{array}$ \\
\hline P5 & $\begin{array}{l}\text { 1992/ } \\
\text { particular }\end{array}$ & $\mathrm{F} / 44$ & $\begin{array}{l}\text { A formação foi apenas o começo e o seu desempenho era limitado. Já melhorou } \\
\text { bastante com a busca por melhoria que ela realizou, porém ainda está querendo } \\
\text { aprender mais sobre metodologia de ensino-aprendizagem. }\end{array}$ \\
\hline P6 & $\begin{array}{l}\text { 2008/ } \\
\text { particular }\end{array}$ & $\mathrm{F} / 28$ & $\begin{array}{c}\text { A graduação pouco contribuiu, já os projetos e outras atividades mostraram como } \\
\text { ser dinâmico como professor, mas a especialização foi o que mais contribuiu por } \\
\text { elucidar como abordar os conteúdos de maneiras diferencias. Acredita realizar um } \\
\text { bom trabalho, ter um bom relacionamento com os alunos e propor atividades e } \\
\text { metodologias diferentes, apesar de predominar a aula expositiva. Quer trabalhar } \\
\text { mais com atividades práticas. }\end{array}$ \\
\hline P7 & $\begin{array}{c}\text { 2012/ } \\
\text { particular }\end{array}$ & $M / 24$ & ------ \\
\hline
\end{tabular}

FONTE: Autoria própria.

As reflexções do MR culminaram no aprofundamento dos perfis e na reflexão que tange a primeira categoria que aborda o reflexo do curso de formação na atuação profissional do docente, analisada a seguir.

\section{HISTÓRICO DE FORMAÇÃO DOS PROFESSORES E O REFLEXO NA ATUAÇÃO}

Durante a confecção do MR, apenas P7 não apresentou resposta. Os demais professores citaram diversos aspectos, o primeiro foi levantado por P1 que trouxe uma relfexão de como foi a sua educação básica que classificou como memorística: “Formação básica eu odiei as disciplinas científicas, em boa parte pela quantidade de informações ao qual fui exposto de forma totalmente memorística" (P1), em outra fala P1 ressalta que, se interessava pouco pelas disciplinas cientificas, porém ao conhecer uma professora de Biologia nova, passou a se identificar com a disciplina: "Fui apresentado a uma nova professora de Biologia que mudaria minha opinião sobre tal disciplina" 
(P1). O interesse pela licenciatura durante a graduação é enfatizado por outros dois professores: "Comecei meu curso de graduação no ano de 2007 em Licenciatura em Ciências Biológicas, sem saber ao certo o que significava o termo licenciatura" (P1) e,

Iniciei a graduação em 2005. Minha turma foi a última a ter opção de cursar licenciatura e bacharelado juntos. Eu, por ter escolhido a área de docência, fui a única a cursas apenas licenciatura. Fiz essa escolha porque ao ser monitora do MUDI me encantei com o trabalho de dialogar com os alunos e professores e, com isso, contribuir para o desenvolvimento intelectual (P6).

Sobre os dilemas enfrentados durante o curso de graduação P2 relata: "Entrei em 2/89 e terminei em 2/94 .Durante esse período tranquei o curso por 4 semestres para trabalhar devido a necessidade financeira" (P2).

A avaliação da qualidade do curso de graduação é evidenciado também no memorial, evidenciando dois posicionamentos entre os professores, primeiro curso ótimo ou bom: “A qualidade do curso, em minha opinião é excelente, pois tive ótimos professores e acesso a materiais excelente, entretanto, uma graduação de 5 anos não é capaz de satisfazer todas as necessidades de um profissional em construção" (P4); "O curso de uma forma geral foi bom, estava em um período de reestruturação e talvez por isso não foi melhor"(P2). Identificou-se nessa avaliação uma críticidade em afirmar que sempre existemproblemas: "Considero que tive bons professores, assim como em todas as instituições, seja ela privada ou não sempre tem algo que se faz necessário correr atrás, pois existem aqueles professores que nunca estão preocupados com o aprendizado e sim com seu salário" (P3). E como afirma P5 sempre há o que melhorar:

Acredito que a qualidade não foi ruim, mas que havia muitos pontos a serem melhorados ainda. Assim que me formei, profissionalmente ainda era muito imatura e insegura. O curso precisa aprimorar mais na questão da prática e vivência do estudo (física, química e astronomia - nem havia matéria sobre esse assunto) com a realidade (P5).

Ressalta-se no trecho anterior, que a formação dos professores vai além da graduação, pois esta é distante da realidade profissional. Aspecto levantado também por professores que avaliam 0 curso como ruim "Faltou associar com a realidade, era estudo da teoria pela teoria" (P5). As críticas durante o periodo de graduação tecem-se sobre às metodologias de ensino, a relação professoraluno, e a ausência de disciplinas voltadas para a licenciatura privilegiando o bacharelado, denotando assim o descontentamento dos professores (P1, P2, P5) e o predominio da modo tradicional de formação: “Muito decoreba, o ensino do professor muito distante do aluno" (P2) e P1:

As aulas eram basicamente expositivas e memorísticas, salvo as aulas práticas que eram mais dinâmicas, porém não menos dogmáticas. Éramos ensinados a 
ser reprodutores de testes laboratoriais, com pouca ou nenhuma discussão sobre os resultados obtidos. A qualidade do curso deixava a desejar em alguns aspectos, pois apesar de ser voltado para a licenciatura, tanto as pesquisas como as aulas enfocavam quase que primordialmente, os aspectos do curso de bacharelado (P1).

Com relação às disciplinas voltadas ao ensino no período da graduação, surgiram críticas e constatações de que foram insuficientes e/ou pouco contrutivas no processo de formação e na atuação como profissional docente: "No começo foi muito difícil pois o que temos na pratica de ensino é muito pouco para realmente preparar alguém para uma sala de aula e você acaba aprendendo tentando acertar e muitas vezes errando muito" (P2); "Hoje com a experiência que tenho vejo que foi pouco, não deu subsídio para uma boa formação, seria necessário professor com mais comprometimento" (P3), "As aulas de graduação voltadas para o ensino como a didática, psicologia de educação e a prática de ensino abordaram os conteúdos da ementa de maneira superficial sem promover reflexão e tampouco estimular os graduandos e seguir a carreira docente" (P6). Na fala de P1 ressalta-se a ausência de professores com a formação na área de ensino, mesmo em um curso finalizado em 2010:

O estágio supervisionado foi extremamente curto, me lembro de ter feito apenas 2 observações em sala e uma aula de regência compartilhada com outro aluno do curso. O TCC não era obrigatório para a licenciatura, no entanto fiz questão de fazê-lo, na área de ecologia, pois não havia orientadores na área educacional (P1).

Observa-se uma crítica, ao modelo de ensino tradicioanal, modelo este que os professores acrditam fugir em suas atuações profissionais: "Comecei no método bem tradicional, no mesmo que fui educada e conforme fui me capacitando é que senti a necessidade de mudanças (P2); "Assim que me formei, acredito que fui igualzinha a esses professores, utilizando-se apenas de aulas expositivas. Acontece que a tecnologia invadiu a vida das pessoas e tivemos que nos adequar" (P5). Outros apesar de ciritcar sentem dificuldades:

Comecei minha atividade profissional, [...] e, sempre busquei rechaçar as práticas de ensino ao qual não me identificava enquanto aluno da educação básica, apesar de diversas vezes me flagrar repetindo atitudes semelhantes, por meio de atividades essencialmente memorísticas; em diversas aulas práticas me deparei apenas reproduzindo apostilas (P1).

Além das críticas ao ensino tradicional, alguns professores apresentam a perspectiva de aprimoramento da atuação profissional: “Acho que já passei por várias metodologias em sala de aula pois o tempo, as mudanças da escola e do alunado exigem que o professor sempre procure 
melhorar, repensar, reformular as suas aulas, rever seus conceitos, enfim, sempre tentar melhorar (P2); “Procuro não ser apenas uma preparadora de aulas, estou sempre buscando a aprendizagem, procuro criar situações dialógicas com educandos, tento usar materiais coerentes com uma proposta de ensino" (P3). Porém, apenas P1 admite praticar uma conduta nos moldes do ensino tradicional: "Contudo, algumas vezes (talvez com mais frequência do que eu imagine) eu me pego sendo o mesmo professor que apenas ensina a memorizar e a repetir. Parece uma luta incessante contra uma prática habitual que não sei ao certo como a adquiri, mas está impregnado em mim" (P1).

Ainda discorrendo sobre como se constituem as atuações dos professores, P4 aponta os recursos didáticos por ela utilizados e ressaltando a discrepância entre a escola pública e a escola particular: "Com relação aos recursos, já trabalhei em escolas sem laboratório e até mesmo biblioteca e também já atuei em escolas com boa infraestrutura e recursos" (P4);

As escolas estaduais dispõem de tv pendrive que faço uso diariamente, quadro e giz. As aulas de Biologia 2 semanais e Ciências 3 aulas semanais, Salas lotadas muitas vrzes sem condições de fazer aulas experimentais indisciplina em sala de aula, em todas as escolas trabalho com alunos de baixa renda, e com estrutura familiar muito precária (P3).

Houve também comentários sobre as formas de avalliação, por três professores: “Avaliação é contínua e diagnóstica, usando avaliação escrita e avaliação de trabalhos" (P3); "Com relação aos instrumentos de avaliação, primo pela avaliação formativa e continuada por meio de atividades, discussões, provas formais e portfólios" (P4); "Para a avaliação também gosto de solicitar trabalhos que envolvam pesquisa e a produção de cartazes, maquetes, entre outros para que os alunos compreender o conteúdo ou algo relacionado a ele de maneira mais complexa relacionando seu dia a dia e problemas sociais (P6). Além de falar de como realizam a avaliação em sala de aula, os professores foram convidados a se auto avaliarem respostas que foram elencadas na segunda categoria posteriormente anallisada.

\section{AUTOAVALIAÇÃO DOS PROFESSORES QUANTO A SER OU NÃO REFLEXIVO}

Como observado no quadro II a seguir, nehum dos professores disse não ser reflexivo.

Quadro II. Autoavaliação dos professores quanto a ser ou não reflexivo.

\begin{tabular}{|c|c|c|}
\hline Autoavaliação & Trechos das falas & Professor \\
\hline Sim & $\begin{array}{c}\text { "Sim considero" / "Sim, me considero" / "Eu me considero uma professora } \\
\text { reflexiva." / "Penso que sim" }\end{array}$ & $\begin{array}{l}\text { P3, P4, P5, } \\
\text { P6 }\end{array}$ \\
\hline As vezes & “Me considero (as vezes)" / "O tempo todo não" & P1, P2 \\
\hline $\begin{array}{l}\text { Acredita que } \\
\quad \operatorname{sim}\end{array}$ & $\begin{array}{l}\text { "Uma vez que desconheço o sentido completo de ser um professor reflexivo, } \\
\text { acredito que dentro do meu conhecimento, sou um professor reflexivo." }\end{array}$ & P7 \\
\hline NÃO & ----------- & ----------- \\
\hline
\end{tabular}

FONTE: Autoria própria. 
Com base nas avaliações que tendem a serem reflexivos, foi solicitado aos professores que expondo caracteristicas justificassem tal avaliação. Nesse sentido foi possível organizar o quadro III, que apresenta estas caracteristicas para considerar-se "como um professor reflexivo":

Quadro III. Características apresentadas pelos professores que se avaliaram reflexivos.

\begin{tabular}{|c|c|c|}
\hline $\begin{array}{l}\text { Característica } \\
\text { s para ser } \\
\text { reflexivo }\end{array}$ & Trechos das falas & $\begin{array}{l}\text { Professor } \\
\text { es }\end{array}$ \\
\hline Reflete & $\begin{array}{l}\text { "Busco refletir sobre os diversos aspectos que influenciam o conceito que vou } \\
\text { trabalhar e, os alunos com quem vou trabalhar." / "Prima pela reflexão sobre minha } \\
\text { prática e melhora da prática de acordo com a reflexão (reflexão sobre a ação e ação } \\
\text { sobre a reflexão)" / "assim que a concluo penso nas minhas atitudes" / "refletindo } \\
\text { para que possa sempre estar melhorando." }\end{array}$ & $\begin{array}{l}\text { P1, P4, } \\
\text { P6, P7 }\end{array}$ \\
\hline $\begin{array}{l}\text { Estar aberto a } \\
\text { mudanças } \\
\text { durante a } \\
\text { aula }\end{array}$ & $\begin{array}{l}\text { "Mas sempre me deixo aberto a novas possibilidades que possam aparecer no } \\
\text { momento da aula (e sempre aparecem), busco utilizar estas interações feitas nos } \\
\text { diversos momentos como um eixo para novas aulas." / "a tentativa de resolver os } \\
\text { problemas e interferências diárias no processo de ensino e aprendizagem." }\end{array}$ & P1, P4, \\
\hline $\begin{array}{l}\text { Incentiva os } \\
\text { alunos a } \\
\text { refletirem } \\
\text { críticamente } \\
\end{array}$ & $\begin{array}{l}\text { Eu procuro fazer meus alunos refletirem, repensarem, tento relacionar o conteúdo } \\
\text { científico com o senso comum e mostrar para ele que é importante não ficar } \\
\text { somente no senso comum. Faço a ligação entre outras disciplinas, relacionando os } \\
\text { meus conteúdos com os dos outros colegas. }\end{array}$ & $\mathrm{P} 2$ \\
\hline $\begin{array}{l}\text { Faz avaliações } \\
\text { do seu } \\
\text { desempenho }\end{array}$ & $\begin{array}{l}\text { "Questionar sobre o que não está bom, como e onde melhorar, aceito sugestões e } \\
\text { repenso minha prática." / " Faço sempre auto-avaliação das minhas aulas." / "assim } \\
\text { que a concluo penso nas minhas atitudes." / " acredito estar sempre avaliando } \\
\text { minhas próprias aulas" / "Que nem sempre dão resultados satisfatórios" }\end{array}$ & $\begin{array}{l}\text { P2, P5, } \\
\text { P6, P7 }\end{array}$ \\
\hline $\begin{array}{l}\text { Têm um } \\
\text { feedback dos } \\
\text { alunos }\end{array}$ & $\begin{array}{c}\text { "Sempre o "feedback" dos meus alunos incluindo-os no processo de reflexão } \\
\text { (autoavaliação)." / "Também sempre converso com os alunos, buscando saber que } \\
\text { tipo de falha e de sucesso realizei, e sempre ao final da disciplina, peço uma carta } \\
\text { com críticas e sugestões as minhas aulas." }\end{array}$ & P4, P7 \\
\hline $\begin{array}{l}\text { Busca } \\
\text { melhorar }\end{array}$ & $\begin{array}{l}\text { "Sempre estou em busca de melhoria." / "Faço minhas anotações no meu } \\
\text { planejamento para que nas próximas vezes eu faça de forma diferenciada e } \\
\text { melhor." / "nas minhas atitudes, nas dos alunos e como poderia ser melhor. / } \\
\text { "Sempre busco melhorar cada aula que será ministrada pela segunda vez, avaliando } \\
\text { o que eu não obtive de resultado na aula anterior." }\end{array}$ & $\begin{array}{l}\text { P2, P5, } \\
\text { P6, P7 }\end{array}$ \\
\hline $\begin{array}{l}\text { Pluralidade } \\
\text { metodológica }\end{array}$ & $\begin{array}{c}\text { "Tento trabalhar de acordo com a pluralidade metodológica para fomentar o } \\
\text { processo de ensino e aprendizagem." / "formas diferentes de ministrar minhas } \\
\text { aulas." }\end{array}$ & P4, P5 \\
\hline $\begin{array}{l}\text { Participar das } \\
\text { atividades da } \\
\text { escola }\end{array}$ & $\begin{array}{l}\text { "Participar das atividades que envolvem a escola e a comunidade escolar, inclusive } \\
\text { busco esta relação nas atividades que desenvolvo na sala de aula." }\end{array}$ & P4 \\
\hline $\begin{array}{l}\text { Busca } \\
\text { conhecimento }\end{array}$ & $\begin{array}{l}\text { "Quero sempre aprender e aprimorar meus conhecimentos e metodologia." / } \\
\text { "Sempre buscando conhecimento / “A razão científica da prática, a ciência da minha } \\
\text { postura perante a educação (quais referenciais teóricos me são base)" }\end{array}$ & $P 2, P 3, P 4$ \\
\hline $\begin{array}{c}\text { Busca } \\
\text { mudança }\end{array}$ & "mudando minha prática pedagógica." & P3 \\
\hline $\begin{array}{l}\text { Formação } \\
\text { continuada }\end{array}$ & "Interesse pela formação continuada autônoma." & P4 \\
\hline
\end{tabular}

FONTE: Autoria própria. 


\section{ASPECTOS QUE DIFICULTAM OS PROFESSORES DE SEREM REFLEXIVOS}

Quadro IV. Características que os dificultam de tornarem-se reflexivos.

\begin{tabular}{|c|c|c|}
\hline Aspectos & Trechos das falas & Professores \\
\hline $\begin{array}{c}\text { Formação } \\
\text { tradicional }\end{array}$ & $\begin{array}{c}\text { Eu fui educada de uma forma bem tradicional e mudar isso que está enraizado } \\
\text { exige muita vontade, esforço, dedicação. }\end{array}$ & P2 \\
\hline $\begin{array}{c}\text { Problemas do } \\
\text { sistema } \\
\text { educacional }\end{array}$ & $\begin{array}{c}\text { "Apesar de admitir que a organização da escola (sistema educacional) muitas } \\
\text { vezes dificulta esta prática por parte do professor." }\end{array}$ & P4 \\
\hline $\begin{array}{c}\text { Não consegue } \\
\text { realizar as } \\
\text { mudanças } \\
\text { propostas }\end{array}$ & $\begin{array}{c}\text { "Quando critico a mim mesma e penso em propostas de como poderia ser } \\
\text { melhor não consigo realizar as mudanças que planejei no ano seguinte." }\end{array}$ & P6 \\
\hline $\begin{array}{c}\text { Sente a } \\
\text { necessidade de } \\
\text { realizar anotações }\end{array}$ & "Então, estou percebendo a necessidade de ter um caderno para fazer essas \\
anotações." & P6 \\
\hline
\end{tabular}

FONTE: Autoria própria.

\section{DISCUSSÃO}

Na primeira categoria observamos o quanto uma formação desconexa da prática pedagógica e nos moldes tradicionais prejudicam, o futuro profissional, e essa defasagem acaba perpetuando o modo tradicional de ensinar, apesar das dificuldades os professores buscam aperfeiçoamento por tentativa e erro na experiência. Nota-se que ao narrar ter aprendido na prática, "em ação" como defende Schön (1992) os professores demonstram a importância da reflexão sobre esta ação, que necessita também de subsídios teóricos para nortear estas experiências, a fim de refletirem sobre o que fazer com os erros e acertos em sala de aula (ZEICHNER, 2008).

Os professores, na segunda categoria, realizaram uma autoanalise e segundo critérios individuais, e todos consideram-se reflexivos, apesar de demonstrar um receio em responder "acredito que sim", o que demonstra a ausência do concepção do conceito de professor reflexivo. Além dessa avaliação realizaram um levantamento das características que consideram representar um professor que reflete. Nota-se que em uma visão geral eles apresentam concepções condizentes, com o que defendem os autores como Schön (1992) e Freire (1996), porém os discursos são repletos de visões simplistas dessas reflexões (ZEICHNER, 2008). No quadro III, os professores que afirmam que a prática reflexiva é avaliar, repensar e modificar, simplificam o conceito do ensino reflexivo, visto que apesar da prática reflexiva incorporar estas ações, Zeichner (2008), ressalta que a reflexão vai além e requer elaboração do pensamento individual e autônomo dos docentes para posterior análise conjunta, a fim de proporcionar reinvindicações e propostas de soluções para mudar a própria realidade. Realizando uma análise 
sobre esses conceitos de Schön e Dewey, os autores primários sobre reflexão na prática pedagógica, Doringon (2008, p. 9), define:

[...] a prática reflexiva na profissão docente é um movimento para colocar em suspensão a prática e para isso é necessário criar condições para a análise, para a crítica, criar modos de trabalho coletivo dentro das escolas, favorecendo uma atitude reflexiva. Refletir sobre sua prática, seu fazer, seu pensar educativo, suas condições de trabalho, sua identidade como profissional, assume constatar como o que faz, reinventa e protagoniza a ação, está constituído social e historicamente. Uma mudança de atitude, de modo de pensar e fazer, de compreender e de explicar é inevitável e necessária.

No Brasil Freire (1996), ao trazer as características necessárias para a prática do professor numa perspectiva autônoma, ressalta que não há docência sem discência. Para que o professor adquira a habilidade de ministrar uma aula é preciso que desenvolva a habilidade de aprender. Nesse sentido, o autor defende ser necessário um conhecimento teórico profundo aliado a capacidade de pesquisa sobre a sua própria prática. Porém, enfoca ao mesmo tempo, o respeito aos saberes dos educados, a aceitação do novo e entre outras características a de que o professor necessita refletir criticamente sobre a prática.

A terceira e última categoria apresenta as dificuldades para a realização destas reflexões citada por três professores (P2, P4 e P6): a formação inicial cursada, o sistema de ensino, a dificuldades de mudar a própria prática e a necessidade de escrever ou realizar anotações periódicas das atividades pedagógicas. A formação inicial e continuada dos professores precisa de melhorias e as pesquisas apontam onde devem ocorrer, Gil-Perez (2009) defende que é preciso na formação inicial superar a concepção do ensino tradicional por meio de uma mudança didática que foca a apropriação de uma concepção de ensino/aprendizagem das Ciências como objeto de construção de conhecimentos. Assim,

[...] tal apropriação, para que se possibilite o deslocamento do modelo vigente de transmissão/recepção, deverá estar teoricamente fundamentada e ser fruto de uma vivência reiterada das novas propostas teóricas, além do período necessariamente breve de uma formação inicial. A preparação docente deverá estar associada, dessa maneira, a uma tarefa de pesquisa e inovação permanentes (GIL-PEREZ, 2009, p. 66).

Além da renovação e inovação constante, outro dilema é o sistema educacional, com a burocratização do ensino público, a falta de estrutura, de materiais, a disposição do currículo, a carga horária excessiva dos professores e os baixos salários desestimulantes, entre outros. Contudo, para efetivar mudanças neste cenário faz-se necessário, políticas públicas e pesquisas na área de ensino de Ciências para ouvir os professores (KRASILCHICK, 2000; ZEICHNER, 2008). 


\section{CONCLUSÃO}

As análises e os resultados do presente artigo, evidenciaram a importância do contexto de formação para a prática do professor de Ciências e Biologia e o quanto a formação inicial e continuada precisam promover atividades que estimulem a reflexão enquanto docentes, visto que só nesta perspectiva, poderão mediar a construção do conhecimento de seus alunos, por meio da reflexão.

\section{REFERÊNCIAS}

BARDIN, L. Análise de conteúdo. Lisboa: Edições 70, 1977.

DORIGON, Thaisa Camargo; ROMANOWSKI, Joana Paulin. A reflexão em Dewey e Schön. Revista Intersaberes, Curitiba, ano 3, n. 5, p. 8 - 22, jan./jul. 2008.

FREIRE, Paulo. Pedagogia da autonomia: saberes necessários à prática pedagógica. São Paulo: Paz e Terra, p. 165, 1996.

GIL-PÉREZ, Daniel. Formação de professores de Ciências: tendências e inovações. São Paulo: Cortez, 2000.

KRASILCHIK, Myriam. Reformas e realidade: o caso do ensino das ciências. São Paulo Perspec. [online]. 2000, vol.14, n.1, pp. 85-93. ISSN 0102-8839. http://dx.doi.org/10.1590/S0102$\underline{88392000000100010}$

LUDKE, M.; ANDRÉ, M. E. D. A. Pesquisa em educação: abordagens qualitativas. São Paulo: EPU, 1986.

PIMENTA, Selma Garrido; GHEDIN, Evandro (Orgs.). Professor reflexivo no Brasil: gênese e crítica de um conceito. São Paulo: Cortez, 2002.

SCHÖN, D. A. Formar professores como profissionais reflexivos. In: Nóvoa (org.) Os professores e a sua formação, Lisboa, Dom Quixote 1992.

ZEICHNER, Kenneth M. Uma análise crítica sobre a "reflexão" como conceito estruturante na formação docente. Educ. Soc., Campinas, v. 29, n. 103, Aug. 2008. 